JOURNAL

of Health Inequalities

\title{
E-cigarette use among Polish students: findings from the 2016 Poland Global Youth Tobacco Survey
}

\author{
Kinga Janik-Koncewicz ${ }^{1,2}$, Mark Parascandola ${ }^{3}$, Jacqueline Bachand ${ }^{4}$, Mateusz Zatoński ${ }^{1,2,5}$, \\ Krzysztof Przewoźniak ${ }^{6,7}$, Witold Zatoński ${ }^{1,2}$ \\ IInstitute - European Observatory of Health Inequalities, Calisia University, Kalisz, Poland \\ ${ }^{2}$ Health Promotion Foundation, Nadarzyn, Poland \\ ${ }^{3}$ National Cancer Institute, Bethesda, Maryland, USA \\ ${ }^{4}$ Office of Research, Evaluation, and Monitoring, Office of Policy Development and Research, US Department of Housing \\ and Urban Development, Washington, USA \\ ${ }^{5}$ Tobacco Control Research Group, Department for Health, University of Bath, UK \\ ${ }^{6}$ Maria Skłodowska-Curie National Research Institute of Oncology Center, Warsaw, Poland \\ ${ }^{7}$ Collegium Civitas, Warsaw, Poland
}

\begin{abstract}
Use of e-cigarettes has increased dramatically in recent years around the world. The aim of this study is to provide comprehensive national estimates of e-cigarette and tobacco use among Polish youth.

A national, representative school-based cross-sectional survey among students was conducted in 2016 in Poland within the Global Youth Tobacco Survey, using a standard self-administered questionnaire, sample design and data collection protocol. A total of 5,154 eligible students ( $51.6 \%$ boys and $48.4 \%$ girls) aged between 11-17 years completed the survey. Among them $26.9 \%$ ( $31.5 \%$ of boys and $21.8 \%$ of girls) were current (use at least once in the past 30 days) e-cigarette users and $20.5 \%$ (21\% of boys and $19.9 \%$ of girls) were current cigarette smokers. Fourteen percent of students were dual users of conventional cigarettes and e-cigarettes. Both cigarette and e-cigarette use increased with age, rural residence, having more pocket money, and having parents or close friends who smoke. There was also a strong correlation between use of conventional cigarettes and e-cigarettes. Current e-cigarette use was $68.7 \%$ among current cigarette smokers, while current cigarette use was 54.8\% among current e-cigarette users.

Daily cigarette smoking among youth has decreased substantially in Poland from $24 \%$ in 1998 to $4.8 \%$ in 2016 in boys, and from $14.4 \%$ to $3.6 \%$ in girls. However, the rapid rise in e-cigarette use poses a potential danger of reversing the tobacco use trend. Continued monitoring is needed to track the use of e-cigarettes and their impact on conventional cigarette use among youth in Poland.
\end{abstract}

KEY WORDS: e-cigarettes, GYTS, youth, tobacco smoking, prevalence, Poland.

ADDRESS FOR CORRESPONDENCE: Kinga Janik-Koncewicz, Institute - European Observatory of Health Inequalities, Calisia University, Nowy Świat 4, 62-800 Kalisz, Poland, e-mail: k.janik-koncewicz@pwsz-kalisz.edu.pl

\section{INTRODUCTION}

While electronic cigarettes (e-cigarettes) and other novel electronic nicotine delivery systems (ENDS) still trail behind conventional cigarette use in most countries, they have gained substantial attention and use in recent years. Two years ago, a special report of the U.S. Surgeon General sounded an alarm around ENDS use among youth, reporting that by 2014 e-cigarettes had become the most commonly used form of nicotine product among U.S. youth, surpassing conventional cigarettes [1]. The report also highlighted the potential adverse health effects of nicotine use among youth, including impacts on adolescent brain development and the presence of toxins in e-cigarette aerosol. 
E-cigarette use is also on the rise in Europe. Filippidis and colleagues [2] used data from the Special Eurobarometer for Tobacco survey to assess trends over time in 27 European countries, concluding that adult ever use of e-cigarettes had increased by over $50 \%$ (from $7.2 \%$ to 11.6\%) between 2012 and 2014. Rates of current e-cigarette use vary across Europe, but in 2014 Poland was among the countries with the highest prevalence.

One study found that the percentage of e-cigarette users in past 30 days among Polish youth aged 15 to 19 years old increased from $5.5 \%$ in $2010 / 2011$ to $29.9 \%$ in 2013/2014 [3]. Another recent study published similar e-cigarette prevalence findings with $27 \%$ of Polish students (ages 13-19) from a socially disadvantaged rural area reporting e-cigarette use in the past 30 days [4]. Due to Poland's e-cigarette market, Polish youth seem to have relatively easy access to e-cigarettes through friends and from vape shops. Thus, it is conceivable that easy access may have contributed to increased e-cigarette use among Polish youth; prior to 2016, unlike other tobacco products such as conventional cigarettes, there was not an age restriction for purchasing e-cigarettes [5].

Increased e-cigarette use is particularly concerning among youth because they are the most susceptible to the harmful effects of nicotine exposure, which include addiction, greater vulnerability to other addictive substances, reduced impulse control, mood disorders, and deficits in attention and cognition [1]. Although data on the longterm health effects of e-cigarette use is limited, e-cigarettes contain harmful and potentially harmful constituents, such as carbonyl and volatile organic compounds, which are known to have deleterious health effects $[6,7]$. Additionally, previous research indicates that e-cigarette use is a gateway to initiation and regular use of other tobacco products, including conventional cigarettes [8-10].

The 2016 Global Youth Tobacco Survey (GYTS) provides the latest data on e-cigarette use among youth in Poland. GYTS is a nationally representative schoolbased survey of students aged approximately 11-18 years old. The aim of this study is to provide comprehensive national estimates of e-cigarette and other tobacco use by sociodemographic and other characteristics, as well as factors associated with current e-cigarette use.

\section{MATERIAL AND METHODS DATA SOURCE}

Analysis was conducted using the 2016 Poland GYTS, a cross-sectional study, carried out by the Health Promotion Foundation. GYTS uses a standard global questionnaire that addresses items relating to tobacco use, such as use of e-cigarettes, smoking cessation, secondhand smoke, access and availability of tobacco products, and knowledge and attitude towards tobacco products. The standard GYTS questionnaire has been translated into Polish. A detailed description of the GYTS methods has previously been reported [11].

\section{PARTICIPANTS AND SAMPLING METHOD}

The study sample included 5,154 eligible students (ages 11-18) in first, second, and third gymnasium classes across rural, small town, and city settings in Poland. Sampling and weighting were conducted separately. All schools with first, second, and third gymnasium classes of 40 or more students were included in the sampling frame. Of the 104 eligible schools and 272 eligible gymnasium classes, 102 schools (98.1\%) and 271 gymnasium classes $(99.6 \%)$ opted to participate in the study. The student response rate was $83.6 \%$ [12].

\section{MEASURES}

\section{Sociodemographic variables}

Sociodemographic measures included in the analysis included gender (boy or girl), age (11-12, 13, 14, 15 or 16-17 or older) and residence (urban or rural). When creating the residence variable, categories for "rural setting" and "small towns" were collapsed into one group labelled as "rural/small town". Pocket money was measured by the question, "During a week, on average, how much money do you have that you can spend on yourself, however you want?" Response categories included in the analysis were less than or equal to 10 PLN and greater than 10 PLN (approximately 2.50 USD).

\section{Current, daily and ever product use}

Students were classified as current e-cigarette users or current conventional cigarette users if they indicated they had used those respective products on at least one day in the past 30-days. Students were categorized as daily e-cigarette users or conventional cigarette users if they had used those respective products every day during the past 30-days. Students were identified as ever e-cigarette users if they indicated they had used e-cigarettes at least one day in their lifetime in response to the question: "In total, how many days have you used an electronic cigarette or e-cigarette in your entire life?" Students were classified as ever conventional cigarette users if they responded yes to the question, "Have you ever tried or experimented with cigarette smoking, even one or two puffs?"

\section{Dual product use}

In this study, individuals were defined as dual product users if they reported use of both e-cigarettes and conventional cigarettes on one or more days in the last 30 days. This was analyzed by creating a categorical variable distinguishing those who reported current use of only e-cigarettes, only conventional cigarettes, both e-cigarettes and conventional cigarettes (dual users), and use of neither product. Individuals were classified as current "e-cigarette only" users if they indicated they had used e-cigarettes at least 1 day in the past 30 days and had used conventional cigarettes 0 days. Individuals were classified as current "cigarette only" users if they indicat- 
ed they had used conventional cigarettes at least 1 day in the past 30 days and had used e-cigarettes 0 days. Current dual users indicated they had used both e-cigarettes and conventional cigarettes at least one day in the past 30 days. Due to missing values, the sample sizes across the subcategories of the dual use variable did not add up to the total number of Polish students in the study sample.

\section{Susceptibility}

Several measures relating to susceptibility to tobacco use were included in the analysis. These items were: "At any time during the next 12 months do you think you will use any form of tobacco?" (yes or no), "Do you think smoking tobacco makes young people more or less attractive?" (more, or no difference, or less) and "Do you think the smoke from other people's tobacco smoking (passive smoking) is harmful to you?" (yes or no). Students were also asked if they had close friends or parents who smoke (yes, some or all, or no).

\section{Advertisement}

Additionally, three measures of exposure to tobacco advertisement were examined: "During the past 30 days, did you see any people using tobacco on TV, in videos, or in movies?" (yes or no), "During the past 30 days, did you see any advertisements for tobacco products on the Internet" (yes or no), and "During the past 30 days, did you see any advertisements or promotions for tobacco products at points of sale (such as: stores, shops, kiosks, etc.)?" (yes or no). For the logistic regression model, these variables were collapsed into a single composite variable such that an individual was categorized as "exposed" if they answered "Yes" to any one of the three advertisement questions.

\section{STATISTICAL ANALYSIS}

$\chi^{2}$ tests were used to summarize descriptive characteristics of Polish students and compare differences between e-cigarette users and conventional cigarette users. A logistic regression was run to explore factors associated with current e-cigarette use. A $p$-value lower than .05 was considered statistically significant. All analyses were conducted using SAS 9.4. Prevalence rates were presented with a confidence interval (CI), and results of the logistic regression as odds ratio (OR) with 95\% CI.

\section{RESULTS}

Among Polish students included in the survey, 26.9\% (31.5\% of boys and $21.8 \%$ of girls) were current e-cigarette users and $20.5 \%$ ( $21 \%$ of boys and $19.9 \%$ of girls) were current conventional cigarette smokers. Fourteen percent of students were dual users of conventional cigarettes and e-cigarettes. Ever use was higher, as $44.5 \%$ had ever experimented with e-cigarettes at some point in the past, while $49.8 \%$ had ever experimented with conventional cigarettes. However, only $4.8 \%$ used e-cigarettes and $5.4 \%$ smoked conventional cigarettes daily. More than half of the students (65\%) had a close friend who smokes cigarettes and $47.3 \%$ had at least one parent who smokes cigarettes (Table 1).

In the univariate analyses, both conventional cigarette and e-cigarette use increased with age, rural/small town residence, having more pocket money, and having parents or close friends who smoke. Tobacco use was also higher among students who expressed positive attitudes or beliefs towards smoking; students who thought smoking makes young people look more attractive and those who did not believe conventional cigarette smoke is harmful (either to the user or to others) were more likely to use both e-cigarettes and conventional cigarettes. Current conventional cigarette and e-cigarette use was also greater among students who reported exposure to tobacco advertising online or at points of sale, compared with those who did not report advertising exposure. Forty three percent of current e-cigarette users and $35 \%$ of current conventional cigarette smokers did not think that smoking is harmful. Overall, $38.3 \%$ of current e-cigarette users and $31.5 \%$ of conventional cigarette smokers reported that they did not believe exposure to smoke from other people was a threat to their health. There was also a strong correlation between use of conventional cigarettes and e-cigarettes. E-cigarette use was higher among students who had experimented with conventional cigarette smoking and among those who reported that they are likely to use a tobacco product in the next twelve months. Current e-cigarette use was $68.7 \%$ among current conventional cigarette smokers, while current conventional cigarette use was $54.8 \%$ among current e-cigarette users (Table 2).

In the multivariate analysis, some of the same patterns hold up when adjusting for other variables. In the multivariate analysis, boys were almost twice as likely as girls to be current e-cigarette users. Students who had experimented with conventional cigarette smoking were more than 6 times as likely to be e-cigarette users, and those who said they think they will use a tobacco product in the next twelve months were 3.68 times as likely to be e-cigarette users. Additionally, e-cigarette use was higher among those with more pocket money ( $\mathrm{OR}=$ 1.75 for those with more than 10 zloty per week), those who thought smoking makes young people look more attractive $(\mathrm{OR}=2.06)$ and those who had close friends who smoke $(\mathrm{OR}=2.18)$. In contrast, use was lower among those who thought exposure to smoke from other people is harmful $(\mathrm{OR}=0.76)$. However, age, urban versus rural residence, exposure to tobacco advertising, and parental smoking were not significant predictors of e-cigarette use in the multivariate model (Table 3). In alternate versions of the multivariate model (removing either question "Have you ever experimented with cigarette smoking?" or "Do you think you will use any form of tobacco in the next twelve months?"), the results were 
TABLE 1. Descriptive characteristics of Polish students

\begin{tabular}{|c|c|c|c|c|}
\hline \multirow{2}{*}{\multicolumn{2}{|c|}{ Characteristics }} & \multicolumn{2}{|c|}{ Proportion } & \multirow[t]{2}{*}{ Number } \\
\hline & & \multirow{2}{*}{$\begin{array}{c}\text { Percent } \\
100\end{array}$} & \multirow{2}{*}{$\frac{(95 \% \mathrm{Cl})}{\mathrm{NA}}$} & \\
\hline Overall & & & & 5154 \\
\hline \multirow[t]{2}{*}{ Gender } & Boys & 51.6 & $(50.0,53.2)$ & 2488 \\
\hline & Girls & 48.4 & $(46.8,50.0)$ & 2642 \\
\hline \multirow[t]{5}{*}{ Age } & $11-12$ years old & 0.5 & $(0.3,0.7)$ & 33 \\
\hline & 13 years old & 8.6 & $(7.8,9.4)$ & 519 \\
\hline & 14 years old & 29.1 & $(27.7,30.5)$ & 1669 \\
\hline & 15 years old & 34.5 & $(32.9,36.0)$ & 1669 \\
\hline & 16-17 years old or older & 27.3 & $(25.8,28.7)$ & 1256 \\
\hline \multirow[t]{2}{*}{ Residence } & Urban & 11.4 & $(10.8,12.0)$ & 1713 \\
\hline & Rural/small towns & 88.6 & $(88.0,89.2)$ & 3441 \\
\hline \multirow[t]{2}{*}{ Pocket money (PLN) } & $\leq 10$ (including 0$)$ & 22.4 & $(21.1,23.8)$ & 1161 \\
\hline & $>10$ & 77.6 & $(76.2,78.9)$ & 3957 \\
\hline \multirow{2}{*}{$\begin{array}{l}\text { Ever experimented with cigarette } \\
\text { smoking }\end{array}$} & Yes & 49.8 & $(48.2,51.4)$ & 2363 \\
\hline & No & 50.2 & $(48.6,51.8)$ & 2679 \\
\hline \multirow[t]{2}{*}{ Close friends smoke cigarettes } & Yes (some or all) & 65.0 & $(63.5,66.5)$ & 3199 \\
\hline & No & 35.0 & $(33.5,36.5)$ & 1812 \\
\hline \multirow[t]{2}{*}{ Parents smoke cigarettes } & Yes (some or all) & 47.3 & $(45.7,49.0)$ & 2227 \\
\hline & No & 52.7 & $(51.0,54.3)$ & 2700 \\
\hline \multirow{2}{*}{$\begin{array}{l}\text { Used cigarettes at least one day } \\
\text { in the past } 30 \text { days (current use) }\end{array}$} & Yes & 20.5 & $(19.2,21.9)$ & 922 \\
\hline & No & 79.5 & $(78.1,80.8)$ & 3969 \\
\hline \multirow{2}{*}{$\begin{array}{l}\text { Used cigarettes daily } \\
\text { in the past } 30 \text { days }\end{array}$} & Yes & 5.4 & $(4.6,6.2)$ & 227 \\
\hline & No & 94.6 & $(93.8,95.4)$ & 4664 \\
\hline \multirow[t]{2}{*}{ Ever used e-cigarettes (in lifetime) } & Yes & 44.5 & $(42.9,46.1)$ & 2183 \\
\hline & No & 55.5 & $(53.9,46.1)$ & 2945 \\
\hline \multirow{2}{*}{$\begin{array}{l}\text { Used e-cigarettes at least one day } \\
\text { in the past } 30 \text { days }\end{array}$} & Yes & 26.9 & $(25.5,28.4)$ & 1308 \\
\hline & No & 73.1 & $(71.6,74.5)$ & 3824 \\
\hline \multirow{2}{*}{$\begin{array}{l}\text { Used e-cigarettes daily } \\
\text { in the past } 30 \text { days }\end{array}$} & Yes & 4.77 & $(4.1,5.5)$ & 228 \\
\hline & No & 95.2 & $(94.5,95.2)$ & 4904 \\
\hline \multirow[t]{4}{*}{ Single or dual use in the past 30 days } & Dual use & 14.0 & $(12.9,15.2)$ & 650 \\
\hline & Cigarette only & 6.4 & $(5.6,7.2)$ & 266 \\
\hline & E-cigarette only & 11.6 & $(10.5,12.6)$ & 536 \\
\hline & Neither & 68.0 & $(66.4,69.5)$ & 3429 \\
\hline
\end{tabular}

Cl-confidence interval, $\mathrm{NA}$ - not available

not substantively different (Table 3). Similarly, removing the question about close friends who smoke did not change the impact of the variable for parental smoking.

\section{DISCUSSION}

This study provides the first nationally representative estimates of e-cigarette use among youth in Poland. These data show that e-cigarette use has overtaken conventional cigarette smoking among adolescents. Almost $27 \%$ of students reported using an e-cigarette in the past 30 days, compared with $21 \%$ of students who reported past 30-day conventional cigarette smoking. The study also reveals several factors associated with e-cigarette use, including male gender, having more pocket money, and having positive associations with tobacco use, such as believing that smoking makes young people look more attractive. Additionally, consistent with previous findings in Poland and other countries, students using e-cigarettes were more likely to have close friends and parents who smoke.

Notably, the data also show a strong overlap between e-cigarette use and use of conventional ciga- 
TABLE 2. Current use of e-cigarettes and cigarettes among Polish students

\begin{tabular}{|c|c|c|c|c|c|c|c|}
\hline \multirow[t]{3}{*}{ Characteristics } & & \multicolumn{3}{|c|}{ Current e-cigarette users } & \multicolumn{3}{|c|}{ Current cigarette users } \\
\hline & & \multicolumn{2}{|c|}{ Proportion } & \multirow[t]{2}{*}{$n$} & \multicolumn{2}{|c|}{ Proportion } & \multirow[t]{2}{*}{$n$} \\
\hline & & $(\%)$ & $(95 \% \mathrm{CI})$ & & $(\%)$ & $(95 \% \mathrm{Cl})$ & \\
\hline \multicolumn{2}{|l|}{ Overall } & 26.9 & $(25.5,28.4)$ & 1308 & 20.5 & $(19.2,21.9)$ & 922 \\
\hline \multirow[t]{2}{*}{ Gender } & Boys & 31.5 & $(29.4,33.7)$ & 736 & 21.0 & $(19.1,23.0)$ & 457 \\
\hline & Girls & 21.8 & $(20.0,23.7)$ & 560 & 19.9 & $(18.1,21.7)$ & 458 \\
\hline \multirow[t]{5}{*}{ Age } & 11-12 years old & 51.4 & $(28.9,73.9)$ & 12 & 45.8 & $(22.6,69.0)$ & 9 \\
\hline & 13 years old & 14.7 & $(11.2,18.3)$ & 71 & 6.5 & $(4.0,9.0)$ & 30 \\
\hline & 14 years old & 22.1 & $(19.8,24.4)$ & 361 & 11.8 & $(10.1,13.6)$ & 197 \\
\hline & 15 years old & 26.7 & $(24.2,29.2)$ & 434 & 20.5 & $(18.2,22.9)$ & 312 \\
\hline & 16-17 years old or older & 35.7 & $(32.6,38.7)$ & 426 & 34.1 & $(31.0,37.2)$ & 371 \\
\hline \multirow[t]{2}{*}{ Residence } & Urban & 23.6 & $(21.4,25.7)$ & 380 & 17.0 & $(15.0,19.0)$ & 253 \\
\hline & Rural/small towns & 27.4 & $(25.8,28.9)$ & 928 & 21.0 & $(19.5,22.5)$ & 669 \\
\hline \multirow[t]{2}{*}{ Pocket money (zlotys) } & $\leq 10$ (including 0 ) & 16.1 & $(13.7,18.5)$ & 188 & 12.4 & $(10.1,14.6)$ & 128 \\
\hline & $>10$ & 30.1 & $(28.4,31.8)$ & 1110 & 22.9 & $(21.3,24.5)$ & 788 \\
\hline \multirow{2}{*}{$\begin{array}{l}\text { Ever experimented with ciga- } \\
\text { rette smoking }\end{array}$} & Yes & 46.4 & $(44.1,48.7)$ & 1094 & - & - & - \\
\hline & No & 7.1 & $(5.9,8.2)$ & 175 & - & - & - \\
\hline \multirow[t]{2}{*}{ Close friends smoke cigarettes } & Yes (some or all) & 34.4 & $(32.5,36.3)$ & 1071 & 28.3 & $(26.5,30.2)$ & 807 \\
\hline & No & 11.3 & $(9.5,13.1)$ & 175 & 5.5 & $(4.2,6.9)$ & 80 \\
\hline \multirow[t]{2}{*}{ Parents smoke cigarettes } & Yes (some or all) & 31.5 & $(29.2,33.7)$ & 679 & 27.5 & $(25.2,29.7)$ & 525 \\
\hline & No & 21.8 & $(20.0,23.7)$ & 545 & 13.9 & $(12.3,15.5)$ & 341 \\
\hline \multirow{2}{*}{$\begin{array}{l}\text { Next } 12 \text { months, do you } \\
\text { think you will use any form of } \\
\text { tobacco }\end{array}$} & Yes & 61.0 & $(57.6,64.4)$ & 650 & 61.6 & $(58.1,65.1)$ & 592 \\
\hline & No & 17.3 & $(15.9,18.7)$ & 625 & 9.3 & $(8.2,10.5)$ & 304 \\
\hline \multirow{2}{*}{$\begin{array}{l}\text { Used cigarettes at least one } \\
\text { day in the past } 30 \text { days }\end{array}$} & Yes & 68.7 & $(65.2,72.2)$ & 650 & - & - & - \\
\hline & No & 14.6 & $(13.2,15.9)$ & 536 & - & - & - \\
\hline \multirow{2}{*}{$\begin{array}{l}\text { Ever used e-cigarettes (in } \\
\text { lifetime) }\end{array}$} & Yes & - & - & - & 42.5 & $(40.0,45.0)$ & 827 \\
\hline & No & - & - & - & 3.8 & $(2.9,4.7)$ & 87 \\
\hline \multirow{2}{*}{$\begin{array}{l}\text { Used e-cigarettes at least one } \\
\text { day in the past } 30 \text { days (current } \\
\text { use) }\end{array}$} & Yes & - & - & - & 54.8 & $(51.6,58.1)$ & 650 \\
\hline & No & - & - & - & 8.6 & $(7.5,9.7)$ & 266 \\
\hline \multirow{2}{*}{$\begin{array}{l}\text { Exposed to people using } \\
\text { tobacco in TV, in videos, or in } \\
\text { movies in last } 30 \text { days }\end{array}$} & Yes & 25.7 & $(24.0,27.5)$ & 798 & 21.3 & $(19.6,23.0)$ & 606 \\
\hline & No & 27.9 & $(25.4,30.3)$ & 462 & 18.4 & $(16.2,20.6)$ & 283 \\
\hline \multirow{2}{*}{$\begin{array}{l}\text { Exposed to tobacco adverti- } \\
\text { sement on the Internet in last } \\
30 \text { days }\end{array}$} & Yes & 34.8 & $(32.0,37.5)$ & 510 & 26.8 & $(24.2,29.5)$ & 365 \\
\hline & No & 23.0 & $(21.3,24.6)$ & 756 & 17.3 & $(15.8,18.8)$ & 523 \\
\hline \multirow{2}{*}{$\begin{array}{l}\text { Exposed to tobacco advertise- } \\
\text { ments or promotions at points } \\
\text { of sale in last } 30 \text { days }\end{array}$} & Yes & 33.5 & $(31.1,35.9)$ & 654 & 26.6 & $(24.3,28.9)$ & 489 \\
\hline & No & 21.8 & $(21.1,23.5)$ & 613 & 15.8 & $(14.2,17.4)$ & 402 \\
\hline \multirow{2}{*}{$\begin{array}{l}\text { Thinks smoking makes young } \\
\text { people look more or less } \\
\text { attractive }\end{array}$} & More & 43.4 & $(37.0,49.8)$ & 142 & 28.5 & $(22.5,34.5)$ & 92 \\
\hline & No difference or less & 25.3 & $(23.8,26.8)$ & 1115 & 19.6 & $(18.2,21.0)$ & 791 \\
\hline \multirow{2}{*}{$\begin{array}{l}\text { Think smoke from other pe- } \\
\text { ople is harmful to you }\end{array}$} & Yes & 24.1 & $(22.5,25.6)$ & 930 & 17.8 & $(16.4,19.2)$ & 648 \\
\hline & No & 38.3 & $(34.7,42.0)$ & 360 & 31.5 & $(27.9,35.1)$ & 259 \\
\hline \multirow{2}{*}{$\begin{array}{l}\text { Do you think smoking is harm- } \\
\text { ful to your health }\end{array}$} & Yes & 23.6 & $(22.1,25.1)$ & 954 & 17.8 & $(16.4,19.1)$ & 667 \\
\hline & No & 43.5 & $(39.5,47.7)$ & 315 & 35.0 & $(30.9,39.2)$ & 229 \\
\hline
\end{tabular}


TABLE 3. Association between current use of e-cigarettes among Polish middle school students and demographic, socio-economic and other variables connected with smoking attitudes and knowledge - multivariate analysis

\begin{tabular}{|c|c|c|c|c|c|c|}
\hline \multirow[t]{3}{*}{ Variables } & \multicolumn{6}{|c|}{ Current use of e-cigarettes among Polish middle school students } \\
\hline & \multicolumn{2}{|c|}{$\begin{array}{l}\text { + Ever experimented with } \\
\text { cigarette smoking } \\
\text { + Do you think you will } \\
\text { use any form of tobacco in } \\
\text { the next } 12 \text { months? }\end{array}$} & \multicolumn{2}{|c|}{$\begin{array}{l}\text { + Ever experimented with } \\
\text { cigarette smoking } \\
\text { - Do you think you will } \\
\text { use any form of tobacco in } \\
\text { the next } 12 \text { months? }\end{array}$} & \multicolumn{2}{|c|}{$\begin{array}{l}\text { - Ever experimented with } \\
\text { cigarette smoking } \\
\text { + Do you think you will } \\
\text { use any form of tobacco in } \\
\text { the next } 12 \text { months? }\end{array}$} \\
\hline & OR & $95 \% \mathrm{Cl}$ & OR & $95 \% \mathrm{Cl}$ & OR & $95 \% \mathrm{Cl}$ \\
\hline Overall & - & - & - & - & - & - \\
\hline \multicolumn{7}{|l|}{ Gender } \\
\hline Boys & 1.93 & $1.59,2.34$ & 1.66 & $1.38,1.98$ & 1.94 & $1.62,2.32$ \\
\hline Girls & ref & - & ref & - & ref & - \\
\hline \multicolumn{7}{|l|}{ Age } \\
\hline $11-12$ years old & ref & - & ref & - & ref & - \\
\hline 13 years old & 1.15 & $0.17,7.69$ & 1.53 & $0.22,10.63$ & 0.57 & $0.10,3.10$ \\
\hline 14 years old & 1.45 & $0.23,9.38$ & 2.05 & $0.31,13.83$ & 0.83 & $0.16,4.37$ \\
\hline 15 years old & 1.27 & $0.20,8.22$ & 1.86 & $0.28,12.54$ & 0.88 & $0.17,4.63$ \\
\hline $16-17$ years old & 1.41 & $0.22,9.14$ & 2.19 & $0.33,14.79$ & 1.07 & $0.20,5.68$ \\
\hline \multicolumn{7}{|l|}{ Residence } \\
\hline Urban & 0.90 & $0.74,1.08$ & 0.95 & $0.80,1.14$ & 0.81 & $0.68,0.96$ \\
\hline Rural/small towns & ref & - & ref & - & ref & - \\
\hline \multicolumn{7}{|l|}{ Pocket money (PLN) } \\
\hline$<10$ (including 0 ) & ref & - & ref & - & ref & - \\
\hline$\geq 10$ & 1.75 & $1.37,2.23$ & 1.77 & $1.40,2.23$ & 1.83 & $1.45,2.30$ \\
\hline \multicolumn{7}{|c|}{ Ever experimented with cigarette smoking } \\
\hline Yes & 6.35 & $5.00,8.08$ & 9.65 & $6.90,10.85$ & - & - \\
\hline No & ref & - & ref & - & ref & - \\
\hline \multicolumn{7}{|c|}{ Exposed to tobacco advertisement in last 30 days $^{*}$} \\
\hline Yes & 0.88 & $0.69,1.13$ & 0.96 & $0.76,1.21$ & 0.93 & $0.74,1.16$ \\
\hline No & ref & - & ref & - & ref & - \\
\hline \multicolumn{7}{|c|}{ Think smoking makes young people look more or less attractive } \\
\hline More & 2.06 & $1.44,2.94$ & 1.97 & $1.40,2.78$ & 2.38 & $1.67,3.40$ \\
\hline No difference or less & ref & - & ref & - & ref & - \\
\hline \multicolumn{7}{|l|}{ Parents smoke cigarettes } \\
\hline Yes (one or both) & 1.05 & $0.86,1.27$ & 1.09 & $0.91,1.31$ & 1.28 & $1.07,1.53$ \\
\hline No & ref & - & ref & - & ref & - \\
\hline \multicolumn{7}{|c|}{ Close friends smoke cigarettes } \\
\hline Yes (some or all) & 2.18 & $1.68,2.82$ & 2.80 & $2.20,3.56$ & 2.87 & $2.26,3.64$ \\
\hline No & ref & - & ref & - & ref & - \\
\hline \multicolumn{7}{|c|}{ Think that smoke from other people is harmful to you } \\
\hline Yes & 0.76 & $0.60,0.96$ & 0.67 & $0.54,0.84$ & 0.77 & $0.62,0.96$ \\
\hline No & ref & - & ref & - & ref & - \\
\hline \multicolumn{7}{|c|}{ Next 12 months, do you think you will use any form of tobacco } \\
\hline Yes & 3.68 & $2.96,4.58$ & - & - & 5.90 & $4.83,7.20$ \\
\hline No & ref & - & ref & - & ref & - \\
\hline
\end{tabular}

*This item combines 3 of the 4 advertising questions in the codebook: 1. "During the past 30 days, did you see any advertisements for tobacco products on the Internet?", 2. "During the past 30 days, did you see any advertisements or promotions for tobacco products at points of sale (such as: stores, shops, kiosks, etc.)?", 3. "During the past 30 days, did you see any people using tobacco on TV, in videos, or in movies?" 
rettes. Students who had experimented with conventional cigarette smoking were more than 6 times as likely to be e-cigarette users, and those who said they think they will use a tobacco product in the next twelve months were 3.68 times as likely to be e-cigarette users. There were more adolescents using both e-cigarettes and conventional cigarettes than there were using either product alone. More than two thirds of conventional cigarette smokers were also using e-cigarettes and almost half of e-cigarette users were also smoking conventional cigarettes. Further analyses are needed to explore the factors contributing to e-cigarette and dual product use.

In the 1980s, Poland was the country with the highest recorded prevalence of smoking worldwide [13] and, as a result, reported the highest level of tobacco-related mortality [14, 15]. After 1990 a nationwide anti-tobacco movement was launched, and in 1995 the Polish parliament implemented a comprehensive anti-tobacco law [16], followed by a national anti-tobacco program with strong involvement from civil society. This constituted one of the most impactful health campaigns in the world [17], and Poland is recognized as a model for control of tobacco use and tobacco-related disease [18]. Poland was one of the first Central and Eastern European countries to introduce a total ban on tobacco advertisement, in response to an aggressive tobacco industry marketing campaign aimed at children and adolescents. These efforts led to the lowest ever recorded prevalence of daily conventional cigarette smoking among youth in Poland (5.4\% in 2016). The 2016 GYTS data also show that the prevalence of tobacco smoking today is similar among boys and girls (with $21 \%$ of boys and $20 \%$ girls currently smoking). This is in contrast with our findings for e-cigarettes, where prevalence is $50 \%$ higher among boys compared with girls.

These findings add to previous data which has been reported for youth tobacco use in Poland. Zatoński et al. [19] described a significant decrease in conventional cigarette smoking prevalence in Poland in both girls and boys since 2000; between 2004 and 2014 daily cigarette smoking by Polish youth decreased by half. At the same time, recent studies have found increased use of e-cigarettes among Polish youth; Goniewicz and colleagues, comparing two cross-sectional surveys among students aged 15-19 years old in two provinces in Poland [3], found current use of e-cigarettes to be substantially higher in 2013/2014 (29.9\%) compared with 2010/2011 (5.5\%). Notably, they also saw an increase in conventional cigarette smoking and in dual product use as well. Another survey among students aged 13-19 years old from a socially disadvantaged rural area in Poland (Piotrkowski district) reported $27 \%$ prevalence of e-cigarette use in the past 30 days [4]. Consistent with our findings, e-cigarette use was higher among boys and among those who had parents or friends who smoke. Another study found that Polish youth appear to have relatively easy access to e-cigarettes through friends and from vape shops [5].

The pattern in Poland is similar to that seen in the U.S., where there has also been a rise in youth e-cigarette use. On November 15, 2018, data were published from the U.S. National Youth Tobacco Survey (NYTS), a nationally representative survey of middle and highschool students [20]. The data revealed that current e-cigarette use had increased among high-school students from $1.5 \%$ in 2011 to $20.8 \%$ in 2018 . It was estimated that there are now over 3 million middle and high-school students using e-cigarettes in the U.S. This trend has been attributed in part to the popularity of a new generation of ENDS products shaped like a USB flash drive, such as JUUL. These products can be used discreetly at school, have high nicotine delivery, and come in flavors that appeal to youth. Juul has not yet been widely available in Poland, but the manufacturer established Juul Labs Poland in 2018 and is reportedly working towards entering the Polish market [21]. Meanwhile, Philip Morris' IQOS heated tobacco product is already being widely marketed in Poland [22].

Recent data from the UK suggest that e-cigarette use may be a risk factor for initiation of conventional cigarette smoking among youth $[23,24]$. However, it is unclear whether and to what extent e-cigarette may be a factor in conventional cigarette smoking among Polish youth Overall, GYTS data from Poland have shown a substantial decrease in regular daily conventional cigarette smoking over the past 20 years, from $24 \%$ among boys and $14.4 \%$ among girls in 1998 to $4.8 \%$ among boys and $3.6 \%$ among girls in 2016 [25]. While e-cigarettes were introduced into the Polish market around 2010, they were not widely marketed and accessible until more recently. Additionally, regulations concerning e-cigarettes were first passed into law in Poland in 2016, just after the latest GYTS was conducted. Currently, the data is insufficient to assess whether and how e-cigarette use among youth in Poland may impact conventional cigarette smoking, but continued close monitoring is required to understand evolving trajectories of tobacco product use among youth in Poland.

The study has some limitations. First, the collected data were self-reported by students and their behaviors may be under- and over-reported. Presented data are limited to school-based students (aged 11-17 years) and may not be representative to all youths. Data also showed a surprisingly high level of smoking (45.8\%) in the 11-12 years age group. This could be explained by the low number of students in this age group $(n=9)$, or could be the result of coding errors or intentional mislabeling of their own age by some students. Additionally, presented data concern only 2016 and do not allow to assess trends over 
time. Better evidence is also needed to understand the status of e-cigarette use among youth, changes over time, and factors associated.

\section{CONCLUSIONS}

Over the past decades, regular daily cigarette smoking among youth has decreased substantially in Poland. The rapid rise in e-cigarette use poses a potential danger of reversing this trend. Continued close monitoring is needed to track the use of e-cigarettes and other novel products and their impact on conventional cigarette use among youth in Poland.

\section{ACKNOWLEDGEMENTS}

The authors would like to thank dr Jarosław Pinkas, dr Marek Posobkiewicz, Aleksandra Lusawa and Anna Matyszkiewicz from the Chief Sanitary Inspectorate for their involvement in the survey. The findings and conclusions in this report are those of the authors and do not necessarily represent the official positions of the U.S. Department of Housing and Urban Development.

\section{FUNDING/SUPPORT}

GYTS Poland was conducted in 2016 by the Health Promotion Foundation in collaboration with the Chief Sanitary Inspectorate and supported by the funding provided by the World Health Organization (WHO) and the US Centers for Disease Control and Prevention (CDC). The funder had no impact on the data analysis, paper write-up, and conclusions.

\section{DISCLOSURE}

The authors report no conflict of interest.

\section{References}

1. Department of Health and Human Services, Centers for Disease Control and Prevention. E-cigarette use among youth and young adults: a report of the surgeon general 2016. Available from: https:// www.cdc.gov/tobacco/data_statistics/sgr/e-cigarettes/pdfs/2016_ sgr_entire_report_508.pdf (accessed: 10 November 2020).

2. Filippidis FT, Laverty AA, Gerovasili V, Vardavas CI. Two-year trends and predictors of e-cigarette use in 27 European Union member states. Tob Control 2017; 26 (1): 98-104.

3. Goniewicz ML, Gawron M, Nadolska J, et al. Rise in electronic cigarette use among adolescents in Poland. J Adolesc Health 2014; 55 (5): 713-715.

4. Kaleta D, Wojtysiak P, Polanska K. Use of electronic cigarettes among secondary and high school students from a socially disadvantaged rural area in Poland. BMC Public Health 2016; 15: 703.

5. Balwicki L, Smith D, Balwicka-Szczyrba M, et al. Youth access to electronic cigarettes in an unrestricted market: a cross-sectional study from Poland. Int J Environ Res Public Health 2018; 15 (7): pii: E1465.

6. Chun LF, Moazed F, Calfee CS, et al. Pulmonary toxicity of e-cigarettes. Am J Physiol Lung Cell Mol Physiol 2017; 313 (2): L193-L206.
7. Drope J, Cahn Z, Kennedy R, et al. Key issues surrounding the health impacts of electronic nicotine delivery systems (ENDS) and other sources of nicotine. CA Cancer J Clin 2017; 67 (6): 449-471.

8. Fillon M. Electronic cigarettes may lead to nicotine addiction. J Natl Cancer Inst 2015; 107 (3): pii: djv070.

9. Goldenson NI, Leventhal AM, Stone MD, et al. Associations of electronic cigarette nicotine concentration with subsequent cigarette smoking and vaping levels in adolescents. JAMA Pediatr 2017; 171 (12): 1192-1199.

10. Leventhal AM, Strong DR, Kirkpatrick MG, et al. Association of electronic cigarette use with initiation of combustible tobacco product smoking in early adolescence. JAMA 2015; 314 (7): 700-707.

11. Warren CW, Jones NR, Peruga A, et al. Global youth tobacco surveillance, 2000-2007. MMWR Surveill Summ 2008; 57 (1): $1-28$.

12. Baska T, Sovinová H, Nemeth A, Przewozniak K, et al; Czech Republic, Hungary, Poland and Slovakia GYTS Collaborative Group. Findings from the Global Youth Tobacco Survey (GYTS) in Czech Republic, Hungary, Poland and Slovakia smoking initiation, prevalence of tobacco use and cessation. Soz Praventivmed 2006; 51 (2): 110-116.

13. Zatoński WA, Zatoński M, Janik-Koncewicz K, et al. Hundred years of cigarette smoking in Poland: three phases of the tobacco epidemic. J Health Inequal 2017; 3 (2): 118-122.

14. Peto R, Lopez A, Boreham J, et al. Mortality from tobacco in developed countries: indirect estimates from national vital statistics. Lancet 1992; 339 (8804): 1268-1278.

15. Zatoński WA, Tukiendorf A, Zatoński M, et al. Lung cancer mortality decline among middle-aged men and women in Poland and the UK. J Health Inequal 2017; 3 (2): 123-126.

16. Zatoński WA. The Polish Anti-tobacco Law - 20 years on. J Health Inequal 2016; 2 (1): 25.

17. Zatoński M, Zatoński WA, Przewoźniak K, Jaworski M. The significance and impact of the Polish Anti-tobacco Law. J Health Inequal 2016; 2 (1): 32-35.

18. GBD 2015 Tobacco Collaborators. Smoking prevalence and attributable disease burden in 195 countries and territories, 1990-2015: a systematic analysis from the Global Burden of Disease Study 2015. Lancet 2017; 389 (10082): 1885-1906.

19. Zatoński WA, Aaro LE, Samdal O, Mazur J. Smoking- or nicotine-free generation, or both? What should be the public health priority? J Health Inequal 2016; 2 (2): 105-108.

20. Cullen KA, Ambrose BK, Gentzke AS, et al. Notes from the field: use of electronic cigarettes and any tobacco product among middle and high school students - United States, 2011-2018. MMWR Morb Mortal Wkly Rep 2018; 67 (45): 1276-1277.

21. Zatonski M. Juul podbija nikotynową stawkę [Juul pushes up the stake]. Puls Biznesu. Available from: https://www.pb.pl/ juul-podbija-nikotynowa-stawke-954130. Published February 24, 2019 (accessed: 10 November 2020).

22. Rynek spożywczy. Philip Morris wprowadza w Polsce nową generację IQOS zastępujących papierosy [Philip Morris introduces new generation of IQOS replacing cigarettes in Poland]. Available from: https://www.money.pl/gielda/wiadomosci/artykul/ 
philip-morris-wprowadza-w-polsce-nowa, 141,0,2422669.html. Published November 28, 2018 (accessed: 10 November 2020).

23. Soneji S, Barrington-Trimis JL, Wills TA, et al. Association between initial use of e-cigarettes and subsequent cigarette smoking among adolescents and young adults. A systematic review and meta-analysis. JAMA Pediatr 2017; 171 (8): 788-797.

24. Aladeokin A, Haighton C. Is adolescent e-cigarette use associated with smoking in the United Kingdom? A systematic review and meta-analysis. Tob Prev Cessat 2019; 5: 15.

25. Zatonski W, Janik-Koncewicz K, Zatonski M, et al. Rapid decline in cigarette smoking among children in Poland. Tob Prev Cessation 2018; 4 (Suppl): A21. Available from: http:// www.tobaccopreventioncessation.com/Rapid-decline-in-cigarette-smoking-among-children-in-Poland,90409,0,2.htm (accessed: 10 November 2020).

\section{AUTHORS' CONTRIBUTIONS:}

MP, JB analyzed data, KJK and MP prepared the first version of the article. All authors contributed to the final version of the publication, approved the final manuscript as submitted and agreed to be accountable for all aspects of the work. 